\title{
Seed dispersal but not seed germination facilitated by seabirds: seed ecology of Cook's scurvy grass
}

\author{
Esther Dale ${ }^{1,3,4^{*}}$, Peter de Lange ${ }^{2}$ and Bruce Burns ${ }^{1}$ \\ ${ }^{1}$ School of Biological Sciences, University of Auckland, Private Bag 92019, Auckland 1142, New Zealand \\ ${ }^{2}$ Science \& Capability, Department of Conservation, Private Bag 68908, Newton, Auckland 1142, New Zealand \\ ${ }^{3}$ Current address: Landcare Research, Private Bag 1930, Dunedin 9054, New Zealand \\ ${ }^{4}$ Current address: Department of Botany, University of Otago, PO Box 56, Dunedin 9054, New Zealand \\ *Author for correspondence (Email: dalee@landcareresearch.co.nz) \\ Published online: 12 May 2017
}

\begin{abstract}
Lepidium oleraceum (Brassicaceae) is a threatened New Zealand plant closely associated with seabird colony environments. We hypothesise that this spatial coincidence arises from seabird dispersal of L. oleraceum seed and/or guano stimulating germination. To test the possibility of seabird epizoochory, we used laboratory studies to examine $L$. oleraceum seed adhesion and tolerance to seawater immersion. To test for stimulation of germination by guano we measured seed germination in increasing concentrations of seabird guano or inorganic fertiliser (to separate a nutrient effect from a possible effect from some other unknown constituent). Seeds developed a sticky mucilage layer after 50 seconds in freshwater and 50\% were able to adhere to dry paper for over 24 months. A higher proportion of seeds germinated after soaking in freshwater $(91 \% \pm 3.1 \%)$ than seawater $(44 \% \pm 4.9 \%)$, and seawater germination was comparable to unsoaked controls $(46 \% \pm 3.1 \%)$. A comparison of germination rates under different concentrations of guano and fertiliser showed no significant differences associated with treatments except germination was inhibited above $1 \mathrm{gNL}^{-1}$. We conclude that seabirds are probable dispersers of $L$. oleraceum seed through external attachment, but germination is not promoted by guano presence.
\end{abstract}

Keywords: epizoochory; mucilage; ornithocoprophilous; plant-animal interactions; seed germination

\section{Introduction}

Differences in seed dispersal mechanisms and germination characteristics are important filters for species recruitment in different habitats (Van der Valk 1981; George \& Bazzaz 1999; Ribeiro \& Borghetti 2014). Recruitment can be influenced by site characteristics positively or negatively. Increased recruitment often occurs through site characteristics that allow directed seed dispersal (e.g. Heinken et al. 2006) or promote germination success (George \& Bazzaz 1999). Differences in the regeneration niches of species arriving at a site can modulate vegetation composition (Grubb 1977). For example, fire-moderated ecosystems include many species that have seed germination triggered by smoke or heat (Gilmour et al. 2000). In the same way, particular seed dispersal strategies can be favoured by site conditions, such as species with buoyant seeds in seasonally flooded forests (Lopez 2001).

Seabird colony environments present a particular combination of environmental conditions characterised by elevated salt and nutrient levels, particularly nitrogen and phosphorus, and the frequent physical disturbance that results from ocean salt spray and seabird activity (Gillham 1956; Ornduff 1965; Mariko et al. 1992; Ellis 2005). These conditions influence vegetation composition at seabird colony sites by enhancing recruitment of species that are tolerant of, or benefit from, these stresses, and/or have seeds that can be dispersed by seabirds. One species associated with seabird colony sites and thought to benefit from seabird activity is Lepidium oleraceum (Norton et al. 1997; Norton \& de Lange 1999). Lepidium oleraceum Sparrm. ex G.Forst. (Brassicaceae; Cook's scurvy grass) is a threatened New Zealand endemic coastal herb confined to the North Island, northern South Island, and the Kermadec and Chatham Islands (de Lange et al. 2013). Lepidium oleraceum and its allied segregate species (see de Lange et al. 2013) are closely associated with seabird colony environments. Lepidium oleraceum has been recorded in association with colonies of a range of seabird species, including penguins (e.g. Eudyptula minor, Eudyptes pachyrhynchus and Megadyptes antipodes), gannets (Morus serrator), terns (Sterna spp.), petrels (Pterodroma spp.), gulls (Larus spp.) and shags (Stictocarbo spp.) (Norton et al. 1997; Norton \& de Lange 1999). However, the mechanisms facilitating this association with nesting bird colonies remain poorly understood.

Understanding the dispersal ecology of threatened plants such as L. oleraceum is important because management seeks to improve the conservation status of threatened species (Thorsen et al. 2009). Many members of the Brassicaceae family exhibit a sticky mucilaginous seed coating when seeds are moistened (Morton \& Hogg 1989). In some of the Brassicaceae family seed mucilage is a mechanism for external seed dispersal by animals, but more often it functions in other ways such as advancing seed maturation, maintaining dormancy, promoting seed hydration or improving seedling growth (Yang et al. 2012). Norton et al. (1997) speculated that seed mucilage may facilitate $L$. oleraceum dispersal through external seed attachment to seabirds. Seed attachment to seabirds has been observed previously (Thorsen et al. 2011), but not experimentally tested. Many seabirds feed at sea for hours or days at a time, often diving below the surface to capture prey (Weimerskirch et al. 2009). Outside the breeding season seabirds are continuously away from the colony site and 
roam widely at sea to feed (Furness \& Monaghan 1987). For external dispersal by seabirds to be a viable dispersal strategy, $L$. oleraceum seed must be able to adhere to feathers or feet for extended periods and retain viability following exposure to salt water. In addition, L. oleraceum is thought to require guano-rich soils for seed germination (Norton et al. 1997), but this requirement has not been experimentally tested.

We hypothesise that: (1) seabirds facilitate the recruitment of $L$. oleraceum to seabird colony sites by inadvertently transporting seeds that attach to them and (2) germination of seed is stimulated by guano. To test these hypotheses, we asked the following questions:

1. What are the conditions required for a mucilage layer to develop around $L$. oleraceum seed and does this promote long-term adherence?

2. How long can L. oleraceum seed soak in salt water and remain viable?

3. Is germination of L. oleraceum seed enhanced with increasing concentrations of seabird guano?

4. Is any effect of guano attributable to elevated levels of major nutrients or some other unknown guano attribute?

We addressed these questions with controlled observations and experiments in the laboratory.

\section{Materials and methods}

\section{Guano and fertiliser preparation}

Guano was collected from a gannet (Morus serrator) colony at Muriwai ( $36^{\circ} 49^{\prime} 58^{\prime}$ 'S, $\left.174^{\circ} 25^{\prime} 27^{\prime \prime} \mathrm{E}\right)$ adjacent to a naturally occurring $L$. oleraceum population on Oaia Island. The guano was sorted to remove feathers and coarse debris; then sieved to separate guano from sand. The guano was then dryblended to a powder and homogenised through a $1 \mathrm{~mm}$ mesh. Inorganic fertiliser Nitrophoska Blue Fertiliser ${ }^{\complement}$ was blended and homogenised in the same way. The nutrient composition of both guano and fertiliser were analysed by the Landcare Research Environmental Chemistry Laboratory (Palmerston North) following methods described in Blakemore et al. (1987). Seabird guano is known to elevate total soil nitrogen, phosphorus, sodium and potassium (Gillham 1956), so we selected these nutrients for analysis. In addition, we included tests for available nitrogen, nitrate, ammonium, available phosphorus, calcium, magnesium and carbon.

\section{Seed adhesion}

Mature seed was collected from nursery-grown plants derived from seed originally obtained from a natural $L$. oleraceum population on Karewa Island (37³1'48'S, $\left.176^{\circ} 07^{\prime} 52^{\prime \prime} E\right)$. Seed was considered mature when silicles had changed from green to brown. Seeds of $L$. oleraceum develop a coating of mucilage when immersed in fresh or seawater almost immediately (Fig. 1). Freshwater was used for subsequent mucilage measurements because we considered that rain was the most likely water exposure that $L$. oleraceum seed would experience while still attached to the parent plant in the wild. The size of the seed mucilage layer was determined using a calibrated dissecting microscope. The length and width of 10 seeds, including any surrounding mucilage, was measured before and after soaking in freshwater for 30 minutes. Ten replicates of 10 seeds were each weighed before and after soaking in freshwater for 30 minutes to determine the volume of water imbibed during soaking to quantify the volume of water required for mucilage development.

The duration of soaking required for mucilage development will indicate which circumstances could provide sufficient water exposure to initiate seed mucilage development in the wild. The duration of water exposure required for mucilage development was tested by soaking 10 replicates of 10 seeds each in water for 5 mins, 10 mins, 15 mins or 20 mins. These
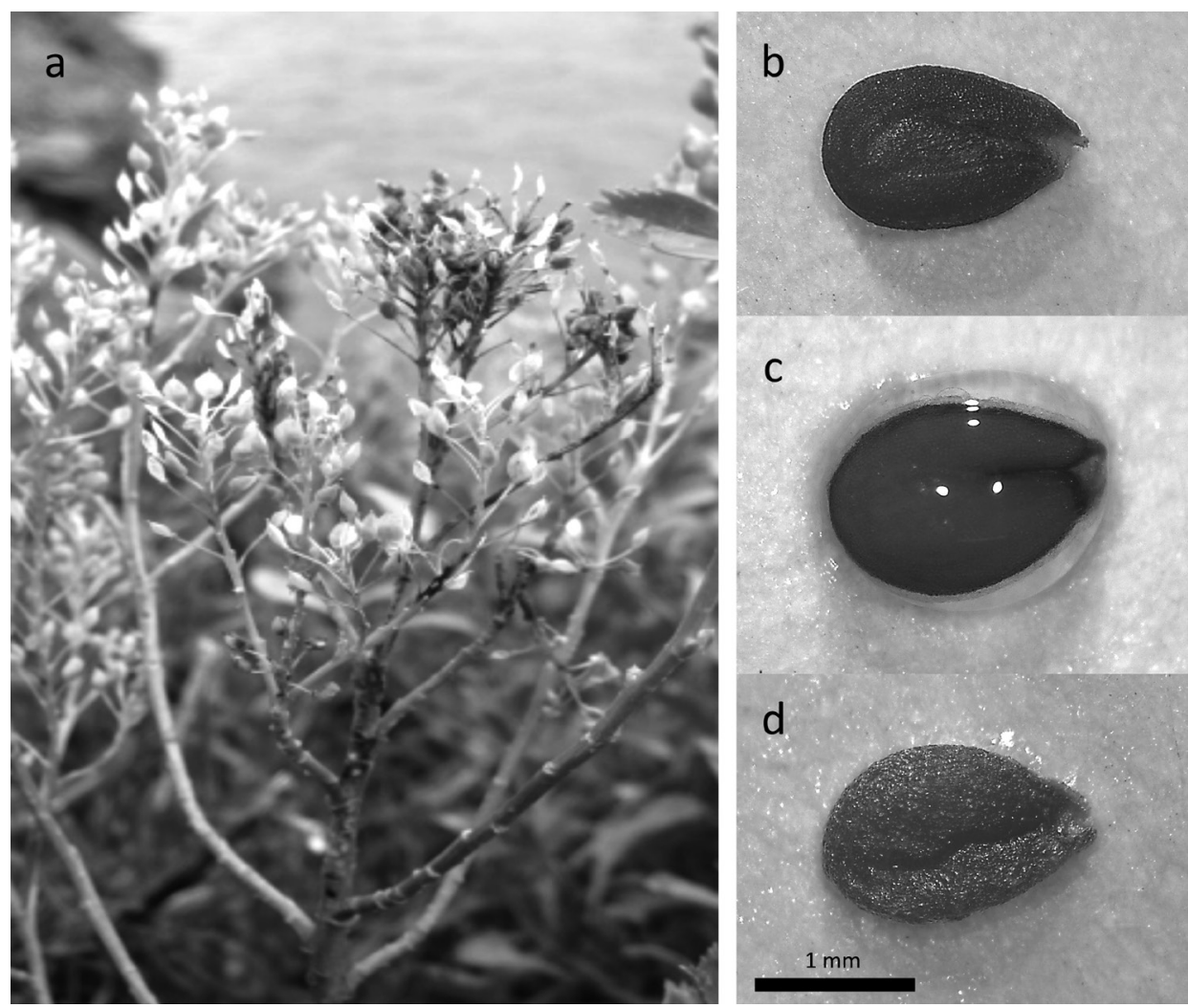

Figure 1. Lepidium oleraceum seed(a) on parent plant, (b) dry prior to soaking, (c) surrounded with mucilage after 30 min soaking and (d) after mucilage has dried. Pictures b-d were taken at $2 \mathrm{x}$ magnification using a dissecting microscope with camera attached. 
times were selected to reflect different levels of water exposure from rain showers of increasing duration. After these times, seeds were placed on tissue paper and examined for mucilage. The persistence of the mucilage layer was determined by transferring 10 seeds with mucilage onto dry paper and checking every 10 minutes to see if mucilage was still present. This was repeated for 20 batches of seed. Mucilage was recorded as present if the seed had a transparent 'halo' or sticky strings of mucilage were observed when a toothpick was pulled away from the seed surface. After mucilage of seeds had dried, the paper was hung vertically and time until seeds fell was recorded to indicate whether attachment would be long enough for effective seed dispersal.

Twenty seeds were also individually observed to determine a more detailed measure of water exposure required for mucilage development that could then be related to types of water exposure potentially experienced by a wild population including salt spray, rain or contact with a wet seabird. These seeds were immersed, then regularly removed from the water and observed for signs of mucilage. Times to the first observations of partial, surrounding, and complete mucilage were recorded for each seed. These correspond to seeds with mucilage that was present, surrounded the seed and had stopped expanding, respectively. The short observation periods when seeds were temporarily out of the water were not included in this timing because further water absorption, and therefore mucilage development, would not occur when seeds were out of water.

Means and standard errors were calculated for each set of measurements and a one-way ANOVA (model assumptions tested graphically) followed up by Tukey's test for honestly significant difference was carried out on the duration of soaking data. All analyses were conducted using R version 3.2.1.

\section{Salinity tolerance germination experiment}

Ten seeds per replicate were soaked in either fresh or seawater for durations of $0,1,2,3$ or 4 weeks with eight replicates of each treatment combination. Freshwater treatments were included to isolate effects of seawater immersion on seed viability from immersion in water per se. The start of soaking was staggered so the end of all soaking times coincided. At the conclusion of the soaking period, the seeds and soaking water were emptied into a cone made of $70 \mathrm{~mm}$ Whatman no. 1 filter paper to drain off the water. This cone was then filled with freshwater to rinse the seeds, left to drain and the number of seeds that had germinated while soaking recorded. The number of seeds germinated during the soaking period indicated how many seeds would germinate prematurely while attached to a foraging seabird coming in contact with seawater.

Seeds from each replicate were then placed on three sheets of Whatman no. 1 filter paper in a petri dish. A pilot study for the guano germination experiment with the Karewa Island seed had suggested that little germination occurred while in freshwater, but almost all seeds germinated in freshwater with the addition of a $1 \mathrm{gL}^{-1}$ fertiliser solution. Therefore $8 \mathrm{~mL}$ of this fertiliser solution were added to petri dishes, which were then sealed. After 14 days the number of germinated seeds was recorded. Data were analysed with a two-way ANOVA (model assumptions tested graphically) and Tukey's honestly significant difference test.

\section{Guano germination experiment}

Seeds were collected for this experiment from approximately ten L. oleraceum individuals on Matariki Island (36 $51^{\prime} 37^{\prime}$ 'S, $175^{\circ} 24^{\prime} 22^{\prime \prime}$ ). Matariki and Karewa Islands are within approximately $100 \mathrm{~km}$ of each other, so we considered plants from these populations would be in the same L. oleraceum meta-population. We lined petri dishes with three layers of $70 \mathrm{~mm}$ diameter Whatman no. 1 filter paper then added $8 \mathrm{~mL}$ of either gannet guano or fertiliser solution applied at five different concentrations, including a $0 \mathrm{gNL}^{-1}$ treatment without nutrients (Table 1). Due to differences in nutrient content between the guano and fertiliser, solutions were prepared to equivalent nitrogen concentrations rather than total

Table 1. Concentrations of major nutrients in solutions of fertiliser and guano used to test the effect of increasing guano concentrations on germination of Lepidium oleraceum.

\begin{tabular}{|c|c|c|c|c|c|c|c|}
\hline \multirow[t]{2}{*}{ Componen } & & \multirow[t]{2}{*}{ Treatment } & \multicolumn{5}{|c|}{ Concentration $\left(\mathrm{gL}^{-1}\right)$} \\
\hline & & & $\mathbf{0}$ & 0.1 & 0.5 & 1 & 5 \\
\hline \multirow{2}{*}{\multicolumn{2}{|c|}{ Total }} & Fertiliser & 0 & 0.770 & 3.830 & 7.670 & 38.340 \\
\hline & & Guano & 0 & 4.210 & 21.050 & 42.100 & 210.480 \\
\hline \multirow[t]{20}{*}{ Nutrients } & \multirow[t]{2}{*}{$\mathrm{C}$} & Fertiliser & 0 & 0.003 & 0.013 & 0.027 & 0.135 \\
\hline & & Guano & 0 & 0.288 & 1.442 & 2.884 & 14.421 \\
\hline & \multirow[t]{2}{*}{$\mathrm{N}$ total } & Fertiliser & 0 & 0.1 & 0.5 & 1 & 5 \\
\hline & & Guano & 0 & 0.1 & 0.5 & 1 & 5 \\
\hline & \multirow[t]{2}{*}{$\mathrm{NO}_{3}^{-}$} & Fertiliser & 0 & 0.063 & 0.317 & 0.635 & 3.173 \\
\hline & & Guano & 0 & 0.006 & 0.032 & 0.064 & 0.318 \\
\hline & \multirow[t]{2}{*}{$\mathrm{NH}_{4}^{+}$} & Fertiliser & 0 & 0.038 & 0.191 & 0.383 & 1.914 \\
\hline & & Guano & 0 & 0.001 & 0.003 & 0.006 & 0.031 \\
\hline & \multirow[t]{2}{*}{$\mathrm{P}$ available } & Fertiliser & 0 & 0.022 & 0.111 & 0.222 & 1.108 \\
\hline & & Guano & 0 & 0.027 & 0.135 & 0.269 & 1.347 \\
\hline & \multirow[t]{2}{*}{ P total } & Fertiliser & 0 & 0.023 & 0.115 & 0.230 & 1.150 \\
\hline & & Guano & 0 & 0.347 & 1.735 & 3.469 & 17.344 \\
\hline & \multirow[t]{2}{*}{$\mathrm{Ca}$} & Fertiliser & 0 & 0.008 & 0.042 & 0.084 & 0.420 \\
\hline & & Guano & 0 & 0.052 & 0.262 & 0.523 & 2.615 \\
\hline & \multirow[t]{2}{*}{$\mathrm{Mg}$} & Fertiliser & 0 & 0.003 & 0.015 & 0.030 & 0.148 \\
\hline & & Guano & 0 & 0.010 & 0.052 & 0.104 & 0.519 \\
\hline & \multirow[t]{2}{*}{$\mathrm{K}$} & Fertiliser & 0 & 0.117 & 0.580 & 1.162 & 5.808 \\
\hline & & Guano & 0 & 0.009 & 0.044 & 0.089 & 0.443 \\
\hline & \multirow[t]{2}{*}{$\mathrm{Na}$} & Fertiliser & 0 & 0.001 & 0.004 & 0.008 & 0.039 \\
\hline & & Guano & 0 & 0.019 & 0.094 & 0.188 & 0.938 \\
\hline
\end{tabular}


concentration of guano or fertiliser. Inorganic fertiliser was used alongside guano treatments to test whether guano germination effects were driven by the nutrient component of the guano, or by some other unknown constituent. Eight L. oleraceum seeds were added to each petri dish. There were seven replicates of each guano and fertiliser combination. Treatment and bench position were randomly assigned, and each petri dish had eight seeds added before sealing with Parafilm. After 14 days we recorded the number of germinated seeds in each dish, with emergence of the radicle indicating germination.

Data were analysed with a two-way ANOVA using R. We tested model assumptions graphically using residual, quantile-quantile residual, scale-location and leverageresidual plots. Significant differences between fertiliser type and concentrations were compared using Tukey's honestly significant difference test.

To allow comparison in germination response between the guano and fertiliser solutions and nutrient concentrations in natural soil at wild $L$. oleraceum population sites, we converted the nitrogen component of our solutions from a concentration to percentage of wet weight. We collected soil within wild populations of L. oleraceum at Matariki Island, Mahuki Island (36 $\left.6^{\circ} 14^{\prime} 2^{\prime \prime S}, 175^{\circ} 17^{\prime} 53^{\prime \prime} \mathrm{E}\right)$ and Stephens Island (4040'2'S, $\left.173^{\circ} 59^{\prime} 60^{\prime \prime} \mathrm{E}\right)$. Two to four samples were collected per island, depending on the spatial distribution of each population. Samples were collected in May, August and June for Matariki, Mahuki and Stephens Islands, respectively. We sampled soil using cores $1.9 \mathrm{~cm}$ in diameter and $10 \mathrm{~cm}$ deep (equivalent to rooting depth) within $0.5 \mathrm{~m}$ of at least $15 \mathrm{~L}$. oleraceum individuals on each island. Samples were combined to form a pooled sample for each site and sealed into plastic bags and kept refrigerated (Markwell \& Daugherty 2003) until they were analysed for nutrient and water content. Analyses were carried out by the Landcare Research Environmental Chemistry Laboratory (Palmerston North) following methods described in Blakemore et al. (1987). Percentage nitrogen of soil wet weight was calculated using the following formula:

$$
N_{w}=\frac{N_{d}}{M+100}
$$

where $\mathrm{N}_{\mathrm{w}}$ is percentage nitrogen of wet weight, $\mathrm{N}_{\mathrm{d}}$ is percentage nitrogen of dry weight and $\mathrm{M}$ is water content as a percentage of the dry weight.

\section{Results}

\section{Seed mucilage}

Mean thickness of seed mucilage was $0.24 \pm 0.03 \mathrm{~mm}$ (mean $\pm 1 \mathrm{SE}$; Fig. 1) and mean volume of water imbibed was $0.977 \pm 0.044 \mu \mathrm{L}$ after soaking in water for $30 \mathrm{~min}$. This is equivalent to an increase in seed width of $54 \% \pm 8 \%$, a seed length increase of $23 \% \pm 3 \%$ and a seed volume increase of $211.7 \% \pm 38.0 \%$. Mean period of immersion in water required before mucilage development was $5.3 \pm 0.6$ seconds for partial development, $19.3 \pm 2.3$ seconds for surrounding mucilage and $50.9 \pm 3.8$ seconds for complete mucilage. Duration of soaking was a significant predictor of complete mucilage occurrence (Fig. 2) and there was a small but significant increase in the number of seeds with complete mucilage after soaking for 15 minutes $(95 \pm 2 \%)$ compared with 5 mins $(80 \pm 3 \%)$. The time taken for mucilage to dry after soaking ranged from $1-55$ mins, with a mean of $21.3 \pm 0.9$ mins. This did not differ significantly with soaking duration. After a week, all except one of the 200

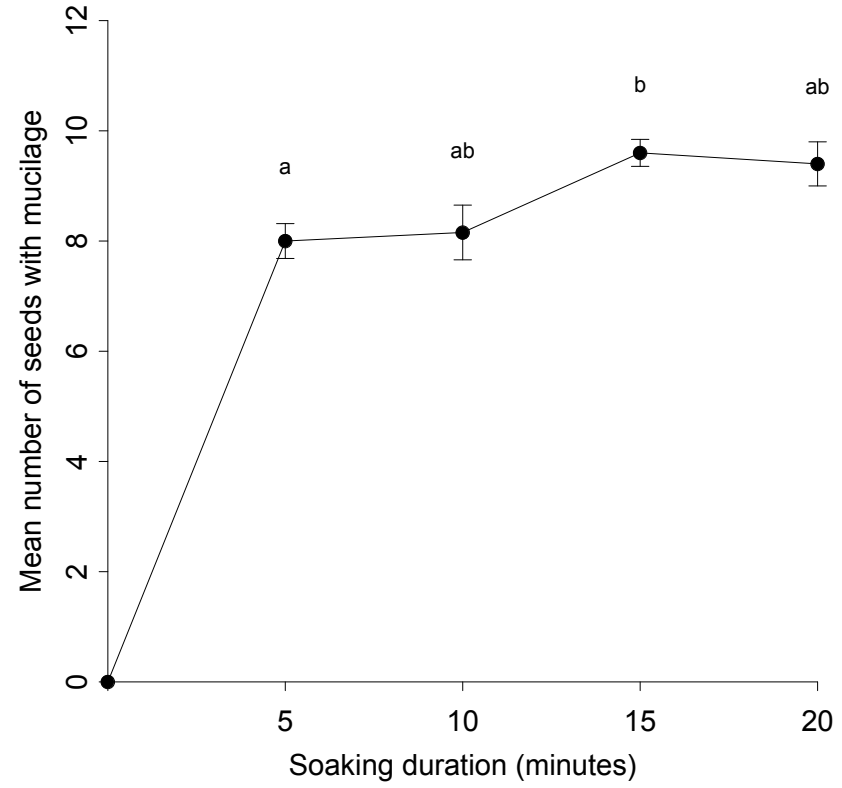

Figure 2. Mean number ( $\pm \mathrm{SE}$ ) of Lepidium oleraceum seeds germinated after different amounts of time soaking in freshwater. ANOVA: $\mathrm{F}_{(3,16)}=4.837, P=0.01$. Treatments not sharing the same letter are significantly different (Tukey HSD, $P=0.04$ ).

seeds remained stuck to a vertical sheet of paper, the single seed that fell off did so after 2.5 days. Seed attachment was $75 \%$ after 9 months and $50 \%$ after 24 months.

\section{Salinity germination effects}

The proportion of seeds that germinated during the soaking period for freshwater treatments increased with soaking duration ( $47.5 \pm 6 \%$ to $85 \pm 4 \%$ ), but no seeds germinated for the controls or during the soaking period for seawater (Fig. 3a, ANOVA: $\left.\mathrm{F}_{(4,70)}=62.2, P<0.001\right)$.

There was a greater rate of germination for seeds that had previously been soaked in freshwater $(90.1 \pm 3.1 \%)$ compared to those that had previously been soaked in seawater $(44.1 \pm 4.9 \%)$ after 14 days. Soaking in freshwater doubled germination compared to the unsoaked controls $(45.6 \pm 3.1 \%$; Fig. 3b). Germination of seeds soaked in seawater and unsoaked controls were equivalent. Both type of water $\left(\mathrm{F}_{(1,74)}=12.6, P\right.$ $<0.001)$ and duration of soaking $\left(\mathrm{F}_{(4,74)}=4.7, P=0.002\right)$ were significant in the two-way ANOVA, but their interaction was not $\left(\mathrm{F}_{(4,70)}=0.7, P=0.61\right)$. Pairwise Tukey's comparisons showed significantly different germination success between water types $(P<0.001)$.

\section{Guano germination effects}

In contrast to our pilot experiment, there was no significant difference in germination rate $(50-75 \%$ of seeds germinating per replicate) for concentrations applied from zero to $1 \mathrm{gNL}^{-1}$ for both guano and fertiliser (Fig. 4). There was significantly lower germination at the $5 \mathrm{gNL}^{-1}$ treatment (mean of 1.5 seeds germinated for guano and none for fertiliser). The two-way ANOVA showed the concentration was significant $\left(\mathrm{F}_{(1,66)}=55.912, P<0.001\right)$, but the type of fertiliser was not $\left(\mathrm{F}_{(1,66)}=0.007, P=0.932\right)$. This outcome was further supported by the pairwise Tukey's comparisons for which the only significant differences $(P<0.001)$ were between $5 \mathrm{gNL}^{-1}$ and the other concentrations (Fig. 4). 

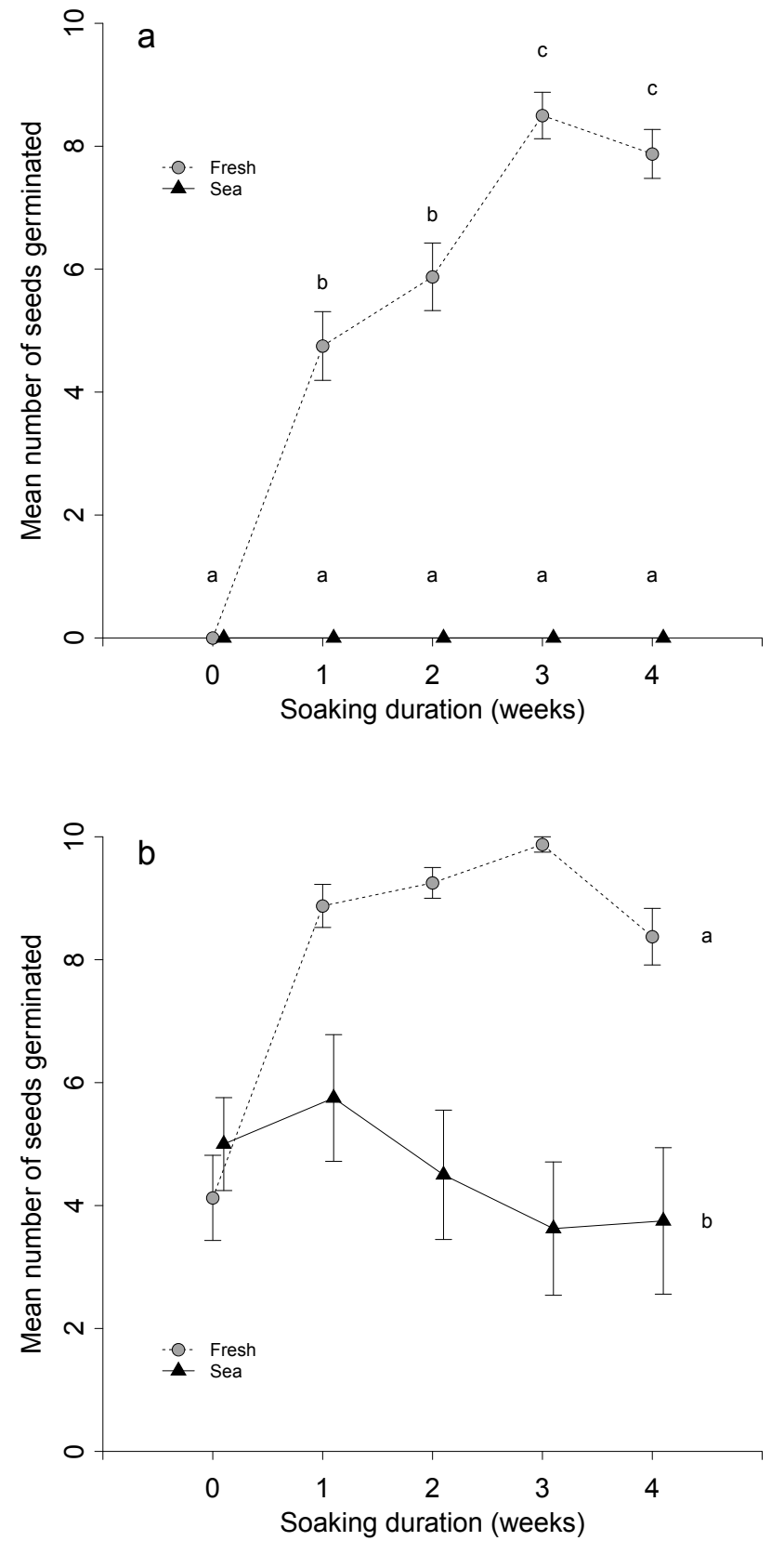

Figure 3. Mean germination ( $\pm \mathrm{SE}$ ) of Lepidium oleraceum seed (a) immediately after soaking in freshwater or seawater and (b) 14 days later. Treatments not sharing the same letter are significantly different (Tukey HSD, $P<0.05$ ).

Percentage nitrogen (total) of soil wet weight in natural L. oleraceum populations was $0.0056 \pm 0.0006 \%$, $0.0064 \pm 0.001 \%$ and $0.0082 \pm 0.003 \%$ for Mahuki, Stephens and Matariki Islands, respectively, which is slightly higher than the concentration of the $0.5 \mathrm{gNL}^{-1}$ solutions $(0.005 \% \mathrm{~N}$ by weight). These are equivalent to $0.99 \pm 0.10 \%, 0.80 \pm 0.10 \%$ and $1.29 \pm 0.49 \%$ nitrogen of soil dry mass for Mahuki, Stephens and Matariki Islands, respectively.

\section{Discussion}

\section{Seed mucilage}

Sticky seed mucilage developed around L. oleraceum seeds after less than one minute of immersion in water, and once out

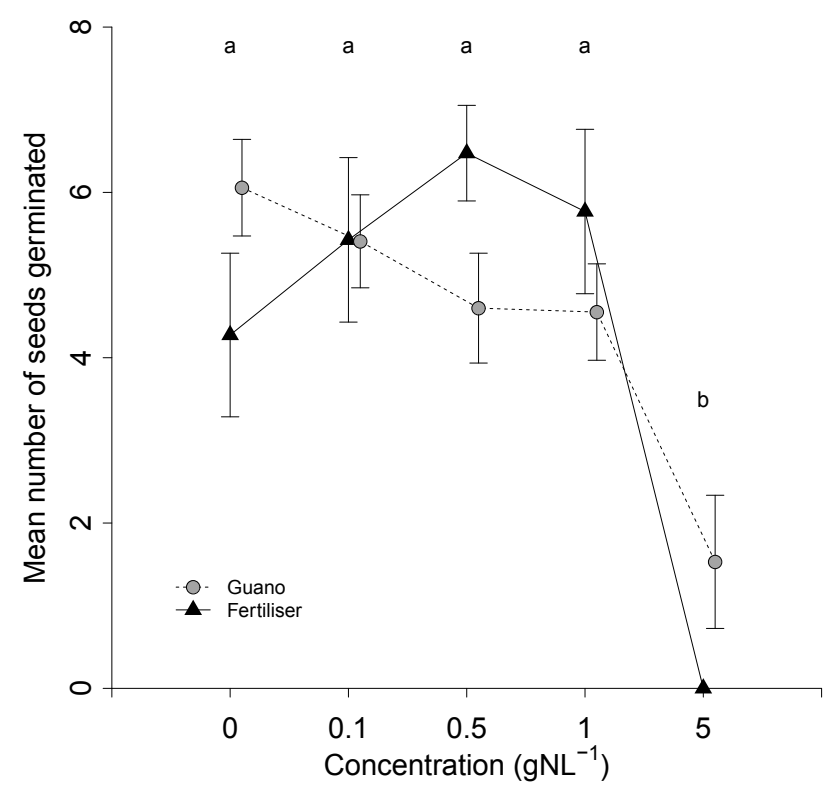

Figure 4. Mean seed germination $( \pm \mathrm{SE})$ of Lepidium oleraceum after exposure to different concentrations of guano or inorganic fertiliser. Treatments not sharing the same letter are significantly different (Tukey HSD, $P<0.05$ ).

of water only remained sticky for an average of 21 minutes. However, seed attachment to a dry surface lasted for at least two years for $50 \%$ of the seeds. Thus rain or salt spray could allow seeds to become sticky for a 20 minute window of opportunity, during which seeds could attach to a bird's foot, leg or feather to be dispersed. We observed that dry seeds would readily attach to moistened surfaces and then become sticky, so wet birds may provide another attachment opportunity. Lepidium oleraceum frequently occurs at seabird burrow entrances, is used as nesting material by surface-nesting species, and is associated with sites frequented for roosting, landing or take-off (see de Lange et al. 2013). The distribution of L. oleraceum within seabird colony sites suggests seabird contact with $L$. oleraceum seeds is highly likely.

Dispersal distances of seeds externally attached to animals depends on duration of attachment, and the speed and direction of the animal's movement (Bakker et al. 1996). Dispersal of L. oleraceum seed by seabirds may potentially occur over long distances because it is tolerant of at least 4 weeks of immersion in seawater, and adhesion is regularly persistent for months to years. This is sufficient time for a seabird to fly the tens of kilometres typical of a foraging trip (Weimerskirch et al. 2009). Unlike Pisonia grandis (Nyctaginaceae) seeds, which lose stickiness after 3 days in seawater (Burger 2005), L. oleraceum seed mucilage and stickiness was maintained after a month soaking in seawater, so prolonged or multiple exposures to water would not compromise seed attachment. Removal by preening birds or by friction during exit or entry of burrows is more likely to dislodge seed, which would result in a favourable dispersal outcome. Seabirds display high site fidelity, typically returning to the same site between foraging journeys (Furness \& Monaghan 1987), therefore dispersal to new sites may be infrequent. Juvenile seabirds prospecting for a breeding site visit non-natal colonies (Péron \& Grémillet 2013), which could provide opportunities for dispersal to multiple sites. This method of external directed dispersal may be an infrequent occurrence because it requires multiple sequential events for adhesion of seed to a dispersing seabird 
and then dislodging the seed at an appropriate site, but this does not preclude it as an effective dispersal method (Carlquist 1967). Further research is required to test the likelihood and duration of attachment of $L$. oleraceum seeds to seabirds in a natural situation, including examining the genetic structure of populations to determine gene flow frequencies that would indicate inter-population dispersal frequencies.

\section{Salinity germination effects}

Lepidium oleraceum seed germinated readily in freshwater, but not seawater. This is consistent with other studies of germination of halophytes in which germination was suppressed at high salinities but seeds were able to subsequently germinate in freshwater (Ungar 1996; Debez et al. 2004; Qu et al. 2008). Imbibition of freshwater is required before germination but is inhibited by seawater due to the low relative water concentration in the presence of such a high salt concentration (Debez et al. 2004). This may be a mechanism to prevent premature germination in the ocean during dispersal.

Lepidium oleraceum seed germination success increased twofold for seeds soaked in fresh compared to seawater or unsoaked controls. However, germination of L. oleraceum seeds continuously immersed in saltwater was equivalent to unsoaked controls, so 4 weeks of seawater exposure did not compromise seed viability. Lepidium oleraceum seed retains viability after soaking in seawater for longer than Pisonia grandis, a seabird-associated tree with sticky seeds dispersed by seabirds. Pisonia grandis seed did not germinate after 12 days immersed in seawater, but $11 \%$ germination did occur after 28 days of 30 minutes per day soaking in seawater as a simulation of attachment to a seabird (Burger 2005). Of the seabirds that occur in association with L. oleraceum (Norton et al. 1997; Norton \& de Lange 1999), different feeding behaviours would result in different seawater exposures. During the summer breeding season seabirds visit land regularly, so seed attachment is more likely to occur then than during winter when they are at sea for months (Furness \& Monaghan 1987). Fruiting of $L$. oleraceum broadly coincides with the seabird breeding season (September to July; de Lange et al. 2013). Maximum exposure to seawater during a single foraging trip in the breeding season would result from complete immersion for the entire duration of a foraging trip. Continual immersion during a foraging trip is exhibited by little blue penguins (Eudyptula minor), which have a mean trip duration of $14.8 \pm 4.1$ hours (Berlincourt \& Arnould 2014). Other species have shorter feeding trips that also involve periods of flight without seawater exposure. One species with shorter feeding trips is the red-billed gull (Larus novaehollandiae) for which $77 \%$ of feeding trips recorded were less than two hours in duration (Tasker \& Mills 1981) and included flight time. Seed seawater exposure would also depend on the part of the seabird to which it attached. Australasian gannet (Morus serrator) foraging trips involve bouts of short dives interspersed with periods of resting on the surface of the water which represent $70-80 \%$ of the foraging trip time (Machovsky-Capuska et al. 2014). Therefore, seeds attached to areas immersed during resting, such as the legs and abdomen, would experience seawater exposure for up to 30 hours in seawater, whereas the upper parts of the body would have shorter seawater immersion. Our results suggest seed of L. oleraceum would easily survive seawater exposure during feeding trips for any of these species. Seed mucilage can aid germination in saline conditions (Yang et al. 2010); it would be interesting to investigate whether the mucilage layer helps maintain seed viability while soaking in seawater.
Germination of seeds soaked in freshwater was higher $(91.0 \pm 3 \%)$ than the unsoaked seed $(45.6 \pm 3 \%)$. Similar experiments with seeds of other seabird dispersed species have also found lower germination in controls than those put in salt or fresh water for some species (Burger 2005; Aoyama et al. 2012). The similarity in germination rates after the soaking of the one week freshwater treatment $(47.5 \pm 6 \%)$ compared to controls at the end of the experiment after 2 weeks on moistened filter paper $(45.6 \pm 3 \%)$ suggests soaking in freshwater may give a head-start to imbibition.

\section{Guano germination effects}

Results of this study did not show strong evidence that seabird guano is directly required for germination of L. oleraceum (despite our pilot experiment being somewhat indicative of this link) and in fact concentrated guano can inhibit germination. The inhibitory concentrations of guano were over two orders of magnitude higher in nitrogen concentration than soil at natural populations. The inhibition response would prevent germination in soil with unfavourable elevated nutrients. To support our finding of germination inhibition by elevated nutrients, we recorded the spatial distribution of all L. oleraceum individuals at each wild population visited, but there were insufficient seedlings present to draw conclusions about seedling distribution patterns. Grant-Hoffman et al. (2010) suggested that increased seedling emergence of species at seabird colony sites compared to non-seabird sites may be due to elevated nutrients. Perhaps for L. oleraceum any positive nutrient effect occurs after seed germination because other research indicates guano enrichment to be an important factor at later life stages (Dale 2013).

The similar inhibited germination response to fertiliser and guano at concentrations greater than $1 \mathrm{gNL}^{-1}$ suggests the inhibitory component had a similar concentration in both guano and fertiliser. Therefore nitrogen, available phosphorus and magnesium are all potentially inhibitory nutrients (Table 1). Nitrogen toxicity is more often problematic than elevated phosphorus in seabird colony environments (Ellis et al. 2011) and was 10 times greater in guano than found associated with natural soils supporting populations of L. oleraceum. Nitrogen toxicity from ammonia, ammonium and nitrite have previously been observed to reduce germination of seed (Cooke 1962; Court et al. 1962; Barker et al. 1970; Westwood \& Foy 1999). Ammonium and nitrate were at least an order of magnitude higher in fertiliser than guano (Table 1), so the lack of similarity between germination of the $0.5 \mathrm{gNL}^{-1}$ fertiliser to $5 \mathrm{gNL}^{-1}$ guano treatments suggests neither ammonium nor nitrate were inhibiting germination. We did not consider nutrient interactions or trace elements (Römheld 2012), so these would have to be examined to be confident of the mechanism driving inhibited germination at elevated concentrations. The lack of seed germination in the fertiliser $5 \mathrm{gNL}^{-1}$ solution compared to some in the equivalent guano treatment suggests L. oleraceum seeds have a greater tolerance for guano than fertiliser. The only nutrients we measured that were present at higher concentrations in fertiliser than equivalent guano solutions were potassium, ammonium and nitrate.

Plant nurseries or others involved in propagation of $L$. oleraceum seeking to maximise germination should ensure the concentrations of major nutrients in the growth substrate are below the inhibitory concentrations of the $5 \mathrm{gNL}^{-1}$ treatments in this study (Table 1). Germinating seed in freshwater without additional nutrients is effective, although after germination additional nutrients improve growth (Dale 2013). 


\section{Conclusion}

The ability of $L$. oleraceum seed to retain viability despite extended immersion in salt water, coupled with an inability to germinate while in seawater and the long attachment time of seed mucilage to surfaces indicate external dispersal by seabirds is a possible dispersal mechanism. However, elevated nutrient concentrations in seabird colony soils do not promote L. oleraceum germination. Therefore, seabirds likely act as a facilitator of initial recruitment of $L$. oleraceum individuals at a site through dispersal, but not as a result of guano deposition.

\section{Acknowledgements}

For permission to collect seed from Matariki Island and collect soil on Matariki, Mahuki and Stephens Islands we acknowledge the iwi Ngāti Koata, Ngāti Maru and Ngāti Rehua who exercise mana whenua over these islands; and Opo Ngawaka for use of his house while staying on Mahuki Island. Thanks to the Department of Conservation staff for support with permits, transport, accommodation and biosecurity. We also acknowledge Auckland Council for access to the Muriwai gannet colony. Thanks to Alwyn Dale, Godfrey Dale, Don Hopkins, and Jamie Stavert for help in the field. Peter Bellingham, KC Burns, Bill Lee, Mike Thorsen and Laura Young gave helpful comments on an earlier version of the manuscript. The senior author acknowledges contributions to the project by the New Zealand Plant Conservation Network (wwww.nzpcn.org.nz) David Given Threatened Plant Research Scholarship, Auckland Botanical Society Lucy Cranwell Scholarship, Auckland University Ralph and Eve Seeyle Postgraduate Scholarship, and Faculty of Science Masters Award. This research was carried out under Department of Conservation Permits NM34190-RES andAK-33217-RES and Auckland Council Permit WS478. Some of the writing was completed during the 2015 New Zealand Ecological Society Conference Writers Retreat.

\section{References}

Aoyama Y, Kawakami K, Chiba S 2012. Seabirds as adhesive seed dispersers of alien and native plants in the oceanic Ogasawara Islands, Japan. Biodiversity and Conservation 21: 2787-2801.

Bakker J, Poschlod P, Strykstra R, Bekker R, Thompson K 1996. Seed banks and seed dispersal: important topics in restoration ecology. Acta Botanica Neerlandica 45: 461-490.

Barker AV, Maynard DN, Mioduchowska B, Buch A 1970. Ammonium and salt inhibition of some physiological processes associated with seed germination. Physiologia Plantarum 23: 898-907.

Berlincourt M,Arnould JP2014. At-sea associations in foraging little penguins. PLoS One 9: e105065.

Blakemore LC, Searle PL, Daly BK 1987. Methods for chemical analysis of soils. NZ Soil Bureau. Lower Hutt, New Zealand, Deptartment of Scientific and Industrial Research. 103 p.

Burger AE 2005. Dispersal and germination of seeds of Pisonia grandis, an Indo-Pacific tropical tree associated with insular seabird colonies. Journal of Tropical Ecology 21: $263-271$.
Carlquist S 1967. The biota of long distance dispersal. V. Plant dispersal to Pacific Islands. Bulletin of the Torrey Botanical Club 94: 129-162.

Cooke IJ 1962. Toxic effect of urea on plants: damage to plant roots caused by urea and anhydrous ammonia. Nature 194: 1262-1263.

Court MN, Stephen R, Waid J 1962. Toxic effect of urea on plants: nitrite toxicity arising from the use of urea as a fertilizer. Nature 194: 1263-1265.

Dale EE 2013. The ecology of Cook's scurvy grass (Lepidium oleraceum s.s.) and its relationship with seabirds. Auckland, New Zealand, University of Auckland. 152 p.

de Lange PJ, Heenan PB, Houliston GJ, Rolfe JR, Mitchell AD 2013. New Lepidium (Brassicaceae) from New Zealand. Phytokeys 24: 1-147.

Debez A, Ben Hamed K, Grignon C, Abdelly C 2004. Salinity effects on germination, growth, and seed production of the halophyte Cakile maritima. Plant and Soil 262: 179-189.

Ellis JC 2005. Marine birds on land: a review of plant biomass, species richness, and community composition in seabird colonies. Plant Ecology 181: 227-241.

Ellis JC, Bellingham PJ, Cameron EK, Croll DA, Kolb GS, Kueffer C, Mittelhauser GH, Schmidt S, Vidal E, Wait DA 2011. Effects of seabirds on plant communities. In: Mulder CPH, Anderson WB, Towns DR, Bellingham PJ eds. Seabird islands: ecology, invasion and restoration. New York, Oxford University Press. Pp. 221-235.

Furness RW, Monaghan P 1987. Seabird ecology. Blackie \& Son Limited, Glasgow. 164 p.

George LO, Bazzaz FA 1999. The fern understory as an ecological filter: growth and survival of canopy-tree seedlings. Ecology 80: 846-856.

Gillham ME 1956. Ecology of the Pembrokeshire Islands: V. Manuring by the colonial seabirds and mammals, with a note on seed distribution by gulls. Journal of Ecology 44: 429-454.

Gilmour CA, Crowden RK, Koutoulis A 2000. Heat shock, smoke and darkness: partner cues in promoting seed germination in Epacris tasmanica (Epacridaceae). Australian Journal of Botany 48: 603-609.

Grant-Hoffman MN, Mulder CPH, Bellingham PJ 2010. Effects of invasive rats and burrowing seabirds on seeds and seedlings on New Zealand islands. Oecologia 162: 1005-1016.

Grubb PJ 1977. The maintenance of species-richness in plant communities: the importance of the regeneration niche. Biological Reviews 52: 107-145.

Heinken T, Schmidt M, von Oheimb G, Kriebitzsch W-U, Ellenberg H 2006. Soil seed banks near rubbing trees indicate dispersal of plant species into forests by wild boar. Basic and Applied Ecology 7: 31-44.

Lopez OR 2001. Seed flotation and postflooding germination in tropical terra firme and seasonally flooded forest species. Functional Ecology 15: 763-771.

Machovsky-Capuska GE, Hauber ME, Dassis M, Libby E, Wikelski MC, Schuckard R, Melville DS, Cook W, Houston M, Raubenheimer D 2014. Foraging behaviour and habitat use of chick-rearing Australasian Gannets in New Zealand. Journal of Ornithology 155: 379-387.

Mariko S, Kachi N, Ishikawa S, FurukawaA 1992. Germination ecology of coastal plants in relation to salt environment. Ecological Research 7: 225-233.

Markwell TJ, Daugherty CH 2003. Variability in $\delta 15 \mathrm{~N}, \delta 13 \mathrm{C}$ and Kjeldahl nitrogen of soils from islands with and without 
seabirds in the Marlborough Sounds, New Zealand. New Zealand Journal of Ecology 27: 25-30.

Morton JK, Hogg EH 1989. Biogeography of island floras in the Great Lakes. II. Plant dispersal. Canadian Journal of Botany 67: 1803-1820.

Norton DA, de Lange PJ 1999. Coastal cresses (Nau) recovery plan. Wellington, Department of Conservation. $71 \mathrm{p}$.

Norton DA, de Lange PJ, Garnock Jones PJ, Given DR 1997. The role of seabirds and seals in the survival of coastal plants: lessons from New Zealand Lepidium (Brassicaceae). Biodiversity and Conservation 6: 765-785.

Ornduff R 1965. Ornithocoprophilous endemism in Pacific Basin angiosperms. Ecology 46: 864-867.

Péron C, Grémillet D 2013. Tracking through life stages: adult, immature and juvenile autumn migration in a long-lived seabird. PLoS One 8: e72713.

Qu X-X, Huang Z-Y, Baskin JM, Baskin CC 2008. Effect of temperature, light and salinity on seed germination and radicle growth of the geographically widespread halophyte shrub Halocnemum strobilaceum. Annals of Botany 101: 293-299.

Ribeiro LC, Borghetti F 2014. Comparative effects of desiccation, heat shock and high temperatures on seed germination of savanna and forest tree species. Austral Ecology 39: 267-278.

Römheld V 2012. Diagnosis of deficiency and toxicity of nutrients. In: Marschner P ed. Marschner's mineral nutrition of higher plants. London, Academic Press. Pp. 299-312.

Editorial board member: Hannah Buckley

Received 4 November 2016; accepted 10 March 2017
Tasker C, Mills JA 1981. A functional analysis of courtship feeding in the red-billed gull, Larus novaehollandiae scopulinus. Behaviour 77: 222-241.

Thorsen MJ, Dickinson KJM, Seddon PJ 2009. Seed dispersal systems in the New Zealand flora. Perspectives in Plant Ecology, Evolution and Systematics 11: 285-309.

Thorsen MJ, Seddon PJ, Dickinson KJ 2011. Faunal influences on New Zealand seed dispersal characteristics. Evolutionary Ecology 25: 1397-1426.

Ungar IA 1996. Effect of salinity on seed germination, growth, and ion accumulation of Atriplex patula (Chenopodiaceae). American Journal of Botany 83: 604-607.

Van der Valk A 1981. Succession in wetlands: a gleasonian appraoch. Ecology 62: 688-696.

Weimerskirch H, Shaffer SA, Tremblay Y, Costa DP, Gadenne H, Kato A, Ropert-Coudert Y, Sato K, Aurioles D 2009. Species-and sex-specific differences in foraging behaviour and foraging zones in blue-footed and brown boobies in the Gulf of California. Marine Ecology Progress Series 391: 267-278.

Westwood JH, Foy CL 1999. Influence of nitrogen on germination and early development of broomrape (Orobanche spp.). Weed Science 47: 2-7.

Yang X, Dong M, Huang Z 2010. Role of mucilage in the germination of Artemisia sphaerocephala (Asteraceae) achenes exposed to osmotic stress and salinity. Plant Physiology and Biochemistry 48: 131-135.

Yang X, Baskin JM, Baskin CC, Huang Z 2012. More than just a coating: ecological importance, taxonomic occurrence and phylogenetic relationships of seed coat mucilage. Perspectives in Plant Ecology, Evolution and Systematics 14: 434-442. 